\title{
SCHIZOPHRENIA AND EPILEPSY; EFFECTIVENESS OF RELAXATION TRAINING FOR CAREGIVERS OF PATIENTS
}

1. Lecturer Psychology The School of Allied Health Sciences, Children's Hospital and the Institute of Child Health, Lahore, Pakistan.

Correspondence Address:

Wahida Anjum

The School of Allied Health Sciences, Children's Hospital Lahore, Pakistan. wahidaanjum@yahoo.com,

Article received on: 20/01/2017

Accepted for publication: $15 / 03 / 2017$ Received after proof reading: 06/05/2017

\begin{abstract}
Wahida Anjum 1
ABSTRACT... Introduction: Persistently dealing with chronic mental illness makes the caregivers suffer from burden and mental health problems which are intensified if the caregiver is female. Therefore, there is need to improve the mental health of caregivers by using relaxation training in such a way that would reduce the burden of care in caregivers. Objectives: It is assumed that female caregivers would be differing significantly in mental health problems as compared to man. Relaxation training would improve mental health as compared to controlling the actual condition. High burden would have inverse relationship with GHQ's differential scores. There would be significant interaction between gender and burden, gender and training, burden and training, gender, burden and training. Study Design: A 2(Gender) X 2(Burden) X 2(Training) mixed factorial between subject design was used. Setting \& Period: This study was conducted within 6 months of duration at the department of Psychiatry, Sir Ganga Ram Hospital Lahore. Material \& methods: Purposive Sample technique was used. Sample consisted of 40 women and 40 men out door patient's caregivers of schizophrenia and epilepsy at Sir Ganga Ram Hospital, Lahore. Their age ranged from 20 to 60 years $(M=35.05$, $S D=0.89)$. We assessed caregiver's burden by using Urdu version of Burden of Assessment (BAS) along with BAS, we also recorded demographic information about the caregivers and assessed patients whom they served on ICD-10 and clinical diagnoses for schizophrenia and epilepsy. Inherent to the study was a General Health Questionnaire (GHQ) which measured health of all caregivers from different dimensions. It included somatic, anxiety \& insomnia, social dysfunction, depression and psychological health of all caregivers. Compliant with a number of researchers, we design a training program to alleviate caregivers burden of health coping strategies, safeguard from unfounded options about the patients and the disease and maximize the efficiency in dealing with the patient and his/her disease. Results: Results found significant main effects on gender as women suffered from high burden and mental health problems as compared to men. A same significant main effect was also found for burden which increased health-related issues. Another significant main effect was found on training. The experimental group whom researcher provided relaxation training was significantly low on GHQ differential score as compared to controlled condition. Since we divided caregivers into high and low burden groups we found that general health of high burden group are more porn to degradation than low burden group. However, low health indicated on GHQ subscales is improved after training for both high and low burden group. Conclusions: We concluded that caregivers need to get substantial understanding of the patients disease and they need to get first-hand knowledge and training of what they are getting into when they are looking after diseased patients.
\end{abstract}

Key words: $\quad$ Caregivers, caregiving, GHQ, BAS, training, schizophrenia, epilepsy.

Article Citation: Anjum W. Schizophrenia and epilepsy; effectiveness of relaxation training for caregivers of patients. Professional Med J 2017;24(5):757-766.

DOI: $10.17957 / T P M J / 17.3837$

\section{INTRODUCTION}

Carer (a person who has accepted responsibility for looking after a patient) and the caregivers are the words that refer to the unpaid members of the family unit like parents, children, siblings, spouse and in-laws. They can be other individuals who belong to the social groups such as neighbors, relatives, friends or significant others. ${ }^{1}$ It also includes the other mental health professionals like psychiatrists, psychologists, social workers, general health practitioners, trained medical nurses, along with fellow patients, clergyman and teachers. They all are the key component of it. All these fellows provide the direct or indirect 
assistance to the sick individuals regardless of the stage and type of illness no matter whether it is neurological, psychological, physiological or mental. ${ }^{2,3}$

Caregiving is usually associated with chronic illnesses or disabilities. ${ }^{4}$ It impairs the functioning and independence of the sick person and makes them dependent on the significant others. Caregivers have to meet their own needs and that of patients simultaneously. ${ }^{5}$ Therefore it creates conflicts, role confusion, physiological, psychological, social, vocational, mental health and emotional problems for the caregivers. Exploratory studies found that psychological distress were significantly high in caregivers as compared to the patients themselves. ${ }^{6}$ According to the Role theory maladaptive roles generate mental health problems. Society assigns roles to the people like mother, father, children, siblings, relatives and friends. A person in some particular role has certain expectations about another person but chronic illness, impairment and disability like schizophrenia and epilepsy creates hurdle to perform their general and specific roles to maintain harmony in social and interpersonal relations. Chronicle illness creates hurdle in the reciprocity of the expected roles and reverse them sometime. For example it is expected from the parents that they nurture the children in early age, if the parents are victim of chronic illness like schizophrenia and epilepsy their role become reversed. This role confusion may generate psychological, physiological, cognitive, emotional, and behavioral problems for the caregivers. Sometimes caregivers may feel sad, guilty, irritable, restless, anxious, frustrated, worthless, helpless and even hopeless about the self and the patients as well. ${ }^{7}$ Researchers. ${ }^{8}$ found significant positive associations between, role confusion, depression, problem in interpersonal relationship and communication among caregivers of patients with schizophrenia.

Caregiving and care receiving can occur at any time in the life. ${ }^{9}$ It affects everyone regardless of language, culture, country, time and space. ${ }^{10}$ It has a multidimensional role, varying from daily routine activities such as household management, checking and monitoring tasks, providing transportation, physical care to recognizing reportable symptoms. ${ }^{11}$ Researchers ${ }^{12}$ found that most of the family caregivers were suffering from severe anxiety and depression. Family routine and financial problems were the most significant predictors of the family burden which impaired the patients' and caregivers' quality of life. In the same way ${ }^{13}$ found that informal caregivers were significantly suffering from psychological $b$ as burden compared to formal caregivers. Type and duration of the problem were inversely affecting the ability to care themselves, their families and the patients as well.

In addition ${ }^{14}$ investigated stress and burden in the caregivers of mentally retarded children. Results showed significant positive relationship between level of stress, burden of care and mental health problems among caregivers of mentally retarded children. In chronic illnesses sometimes caregivers adopt humiliating attitude towards care recipient and show disrespect, get them insulted, commit offenses against them, ridicule them, sometimes even they underestimate their potentials and show teasing behaviors to the patients. ${ }^{15}$ Anger was a prevailing factor between potentially harmful behavior and anxiety. Moreover depression was significantly associated with subjective burden and anxiety as compared to objective burden while anger was inversely related to the mental health. ${ }^{16}$ Long term caregiving commitment enhances the negative emotions such as anger, rage, and stress for the caregivers which are not only troublesome and difficult but also hard to put up with it physically and emotionally. ${ }^{17}$ Patient's maladaptive, impaired and dysfunctional behaviors creates hazards, disturbances and burden for the caregivers and cost to the caregivers' own physical, emotional, social, psychological and mental health problems. ${ }^{18}$

Researchers $^{19}$ conducted a study on the caregivers strain and bereavement. It was a comparative study between husbands and daughters of caregivers of breast cancer hospice patients. Findings revealed that husbands were suffering from more grief, anxiety and depression 
along with psychological and mantel health problems than daughters. Moreover their scores were high on adjustment and emotional problems comparatively. In the same way, psychological distress in caregivers of patients with neurological disorders was investigated and found that experimental and control groups were significantly different in terms of emotional distress. Moreover the group who followed the emotion and focusing on coping strategies was less suffering from emotional distress as compared to other group who followed the problem focused strategies. ${ }^{20}$

All over the world lots of studies have been conducted in health settings and most of them have just focused on patients regardless of language, culture, ethnic group and religion. Literature review indicates that extensive scientific knowledge is available related with etiology, epidemiology and treatment patterns of the patients. ${ }^{21,22}$ Although all such studies are important for the patient's context but it has nothing to do with their caregivers who play major and important role in their recovery. It is observed that psychiatrists, psychologists, therapists, social workers and all other health professionals and practitioners ignore the caregivers while making their treatment plans for the patients. There are some studies focusing on the caregivers although the work is significant but is insufficient to improve the existing conditions of caregivers and attendants. So there is a dire need to extensively work in this area to provide a plan to the clinicians to focus on the burden of care among caregivers of patients with, schizophrenia and epilepsy. There has been plenty of researches to investigate the etiology, epidemiology and treatment patterns with most of them focusing on the patients, not much has been investigated the family members who take care of the patient. ${ }^{23}$ Clinicians hardly give any attention to the needs of caregiver. This ignorance made them expected patients. Therefore, there is a need to investigate the multidimensional factors and aspects of burden for caregivers of patient with schizophrenia and epileptic disorders. Keeping in view the above mentioned literature review it is assumed that female caregivers would be differing significantly in mental health problems as compared to man. Relaxation training would be improved mental health as compared to control condition. High burden would have inverse relationship with GHQ's differential scores. There would be significant interaction between gender and burden, gender and training, burden and training, gender, burden and training.

\section{METHOD}

\section{Participants}

Sample of this study were 40 women and 40 men caregivers of patients with schizophrenia and epileptic disorders with an age range of 20$60+$ years $(M=35.05, S D=0.89)$. Sample was consisted on Out Door Patient (OPD) at Sir Ganga Ram Hospital, Lahore.

\section{MATERIALS}

Participant's age, gender, education level, socioeconomic status, family system and marital status were recoded on the demographic form. Criteria of ICD-10 were used to assess the schizophrenic patients and other clinical assessments were taken to classify epileptic patients.

\section{The Burden Assessment Scale (BAS)}

The Burden Assessment Scale (BAS) assesses burden and consisted on 19 items with the distribution of 1-10 objective and rest of 9 items of subjective burden. ${ }^{24,25}$ Objective burden was conceived as potentially observable behavioral effects of caregiving in different domains including financial problems, limitations on personal activity, household disruptions, and social interactions. Subjective burden, included feelings, attitudes, expressed emotions about the caregiving experiences. ${ }^{26}$ It also was including shame, stigma, guilt, resentment, grief, and worry. It is 5-point Likert type scale where participants respond, 1 to mean not at all and 5 to mean not applicable. The internal reliability of the scale estimated by Chronbach's alpha was found to be .91 and .89. Composite scores of BAS will be used. 


\section{The General Health Questionnaire (GHQ)}

The General Health Questionnaire (GHQ) is a self-administered screening test to identified psychiatric disorders among respondents in community and non psychiatric clinical settings, such as primary care of general medical out patients. ${ }^{27}$ To assess the internal consistency of the items in the test split half reliability was computed on the 853 completed questionnaires and it was shown to be 0.95 . Test-retest reliability coefficient, on three groups of patients who completed the GHQ on two occasions six months apart; were $0.90,0.75,0.51$ respectively. It has 28 item scaled versions with 4 subscales, measured somatic symptoms, A1-A7 anxiety and insomnia, B1-B7 social dysfunction $\mathrm{C} 1-\mathrm{C} 7$ severe depression, D1D7. Responses to each item are scored a 0-3, where not at all equaled 0 and much more than usual equaled 3. Composite scores of GHQ will be used.

\section{Design}

A 2(Gender) X 2(Burden) X 2(Training) mixed factorial between subject design was used in this study. Training had two levels relaxation and controlled condition and burden with high and low level. One dependent variable GHQ having four subscales, somatic, anxiety \& insomnia, social dysfunction and depression. Composite scores on BAS and differential scores of GHQ was served as measures in the analysis by Analysis of variance ANOVA and Post-hoc Tukey HSD test.

\section{Procedure}

Initially 100 caregivers were approached but 80 were completed the whole procedure. After informed consent from the caregivers they were randomly divided into 8 groups 10 in each. 20 woman with high burden 10 in experimental group and provided them relaxation training and 10 in controlled condition. In the same way 20 woman with low burden were divided into two groups 10 in controlled condition and 10 in an experimental group. Same procedure was applied on the man. Researcher administered Urdu translated version of BAS and GHQ questionnaire on the subjects to take their pre burden and mental health ratings. Then 16 muscles relaxation technique were provided to the 20 man 10 with high burden and 10 with low burden and 20 men with low and high burden remained in the controlled condition. Post burden and mental health measurements from experimental and controlled groups were taken after 10 follow up sessions which consisted on almost 2 and half months. At the end session, participants would be thanked and entertained with refreshments such as soft drinks and sandwiches.

Results presented in Table-I indicate a significant main effects on gender at $F(1,72)=45.66 p<$. 001 . Women suffered from high on $(M=16.73$, $\mathrm{SE}=1.98)$ as compared to men $(\mathrm{M}=26.50$, SE $=3.23$ ). A same significant main effect was also found for burden at $F(1,72)=30.39 p<.001$. Burden measures on BAS suggested that high burden lead to increased health-related issues (M $=25.60, \mathrm{SE}=3.37$ ) as compared to low burden $(\mathrm{M}=7.63, \mathrm{SE}=1.83)$. Another significant main effect was found on training at $F(1,72)=352.86 p$ $<.001$. The experimental group whom researcher provided relaxation training was significantly low on $\mathrm{GHQ}$ differential score $(\mathrm{M}=28.07, \mathrm{SE}=2.48)$ as compared to controlled condition ( $\mathrm{M}=9.84$, $\mathrm{SE}=0.89$ ) See figures 1,2 and 3 for comparison of means.

\begin{tabular}{|l|c|c|c|c|c|}
\hline \multicolumn{1}{|c|}{ Sources of Variance } & SS & df & MS & F & p \\
\hline Gender & 1911.01 & 1 & 1911.01 & 45.66 & 0.000001 \\
\hline Burden & 1272.01 & 1 & 1272.01 & 30.39 & 0.000001 \\
\hline Training & 14769.61 & 1 & 14769.61 & 352.86 & 0.000001 \\
\hline Gender X Burden & 1.01 & 1 & 1.01 & 0.02 & 0.9 \\
\hline Gender X Training & 1162.81 & 1 & 1162.81 & 27.78 & 0.000001 \\
\hline Burden X Training & 2091.01 & 1 & 2091.01 & 49.96 & 0.000001 \\
\hline Gender X Burden X Training & 37.81 & 1 & 37.81 & 0.90 & 0.3 \\
\hline Error & 3013.7 & 72 & 41.86 & & \\
\hline
\end{tabular}

Table-I. Analysis of Variance Gender, Burden and Training on General Health of Caregivers $(\mathrm{N}=100)$ 


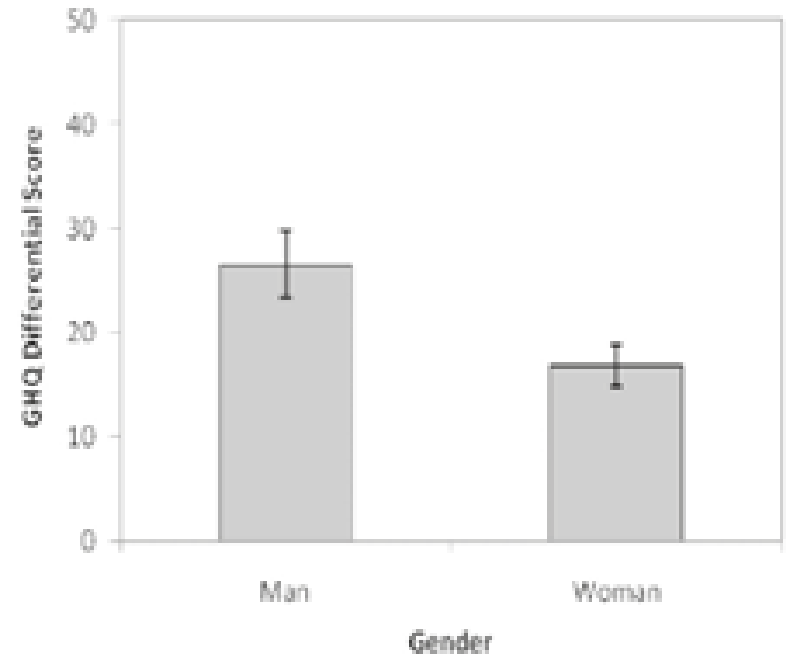

Figure-1. Representing mean difference values which indicated significant differences in the GHQ differential scores of man and women. Standard Errors are represented in the figure by the error bars attached to each column.

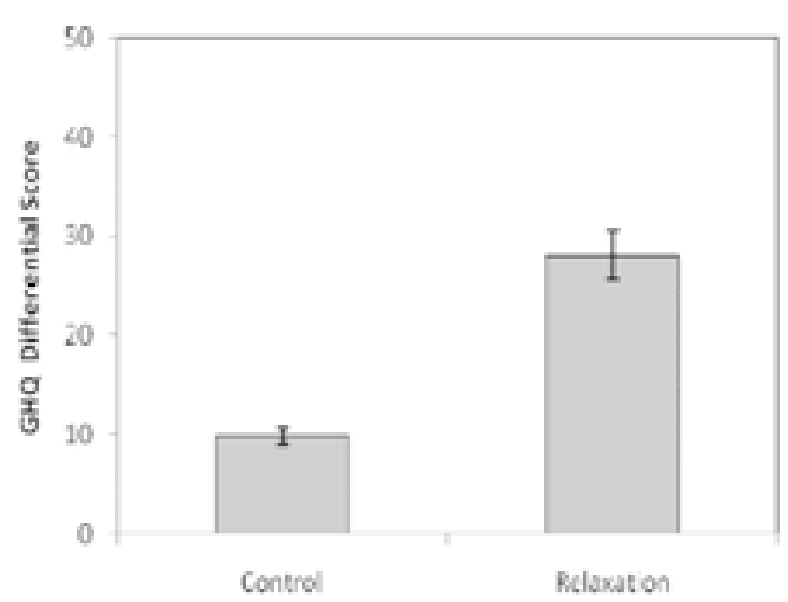

Training

Figure-2. Representing mean difference values which indicated significant differences in the GHQ differential scores of those subjects who have received relaxation training and those who are in controlled condition.

Standard Errors are represented in the figure by the error bars attached to each column.

\begin{tabular}{|c|c|c|c|c|c|}
\hline & Categories & & & & \\
\hline \multicolumn{6}{|c|}{ Gender $\mathbf{X}$ Training } \\
\hline & & Man & Man & Woman & Woman \\
\hline & & Relaxation & Control & Relaxation & Control \\
\hline Man & Relaxation & & 0.0002 & 0.0002 & 0.0002 \\
\hline Man & Control & & & 0.0002 & 0.7 \\
\hline Woman & Relaxation & & & & 0.0002 \\
\hline Woman & Control & & & & \\
\hline \multicolumn{6}{|c|}{ Training $X$ Burden } \\
\hline & & High & High & Low & Low \\
\hline & & Relaxation & Control & Relaxation & Control \\
\hline High & Relaxation & & 0.0002 & 0.0002 & 0.0002 \\
\hline High & Control & & & 0.0002 & 0.7 \\
\hline Low & Relaxation & & & & 0.0002 \\
\hline Low & Control & & & & \\
\hline
\end{tabular}

A non-significant interaction was found between gender and burden. On the other hand significant interaction was found between gender and training at $F(1,72)=27.78 p<.001$ man's $\mathrm{GHQ}$ differential score in controlled condition was $(\mathrm{M}=$ 9.10 , SE $=1.11$ ) which is significantly increased through relaxation training $(\mathrm{M}=43.90$, $\mathrm{SE}=$ 3.11 ) in the same way women's GHQ differential score in controlled condition was $(\mathrm{M}=6.95$, $\mathrm{SE}$ $=0.60$ ) which is significantly amplified through relaxation training $(M=26.50, S E=2.38)$. Results indicated another significant interaction between burden and training at $F(1,72)=49.96 p<.001$.
We found that $\mathrm{GHQ}$ / differential scores for control condition had not difference between low ( $\mathrm{M}=$ 9.15, SE $=1.06)$ and high $(\mathrm{M}=6.90, \mathrm{SE}=0.67)$ burden level. However results revealed a high change in GHQ differential scores after relaxation. It is improved general health on low burden group $(\mathrm{M}=26.10, \mathrm{SE}=2.26)$ greater than low burden group at control. Similarly high burden group (M $=44.30, \mathrm{SE}=3.07$ ) improved their general health scores after relaxation for their control condition. While there were no significant interaction were found between gender, burden and training. See figure 3, 4, 5, 6 and 7 for more details. 


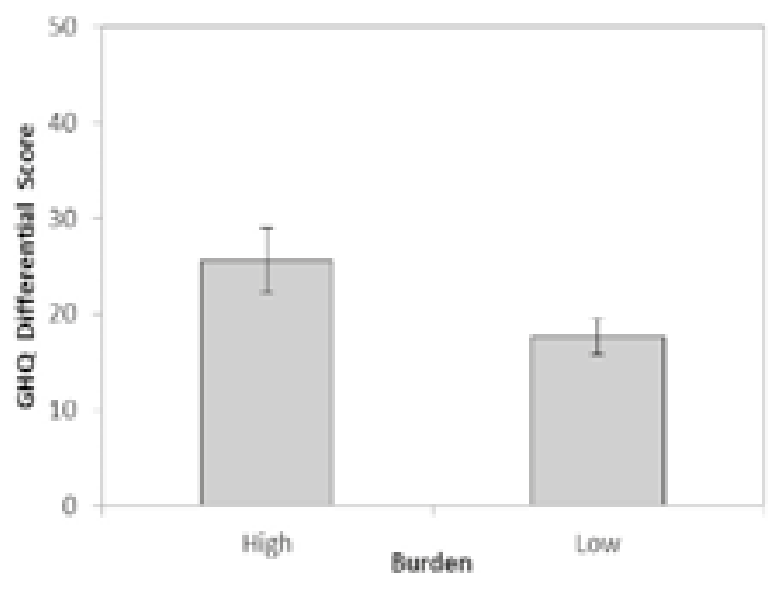

Figure-3. Representing mean difference values which indicated significant differences in the GHQ differential scores of high burden and low burden. Standard Errors are represented in the figure by the error bars attached to each column.

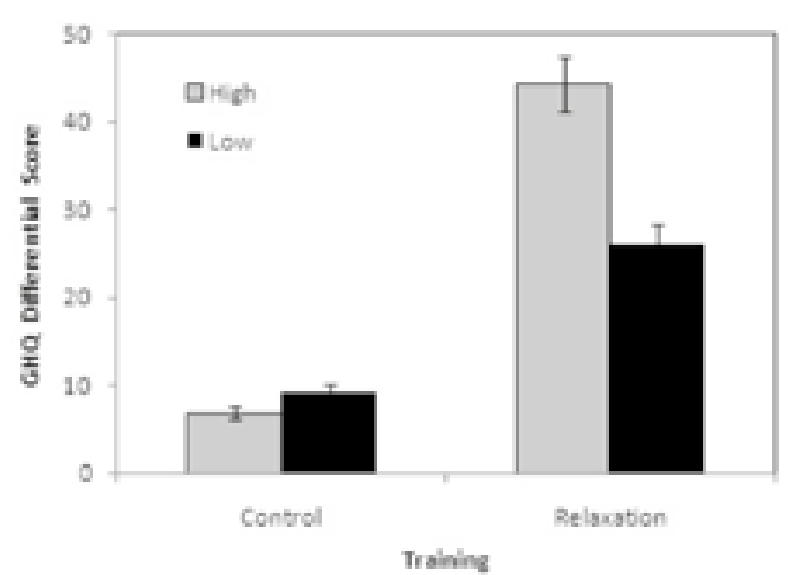

Figure-5. Representing significant interaction between training and burden: This showed that relaxation training improved high and low burden but GHQ differential scores improved noticeably in high burden. Standard Errors ae represented in the figure by the error bars attached to each column.

\section{DISCUSSION}

It was hypothesized that women caregivers would suffered more mental health problems as compared to man, results were supported that assumption and the findings are also remain consisted with the previous researches which found that mothers rather than fathers of children with intellectual disabilities were suffering from high burden. Education, employment and socioeconomic status were the significant predictors of the burden. ${ }^{28,29,30}$ One possible

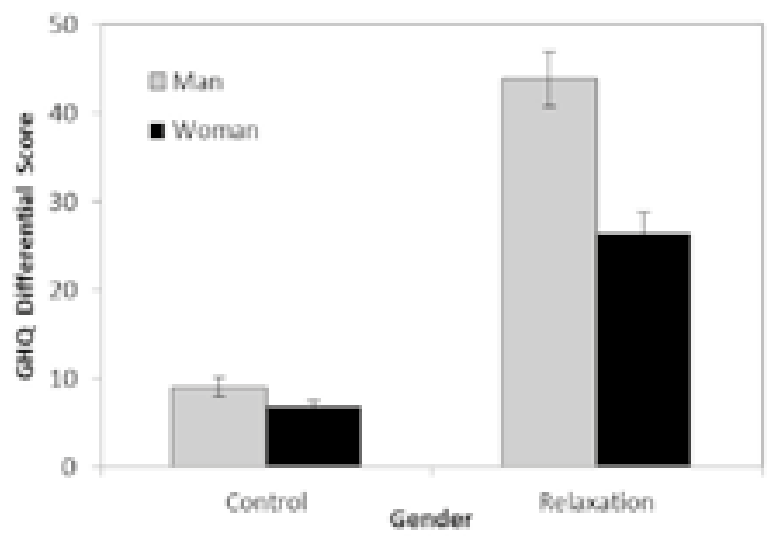

Figure-4. Representing significant interaction between training and gender:

In control condition both men and women have low GHQ differential scores.

Standard Errors are represented in the figure by the error bars attached to each column.

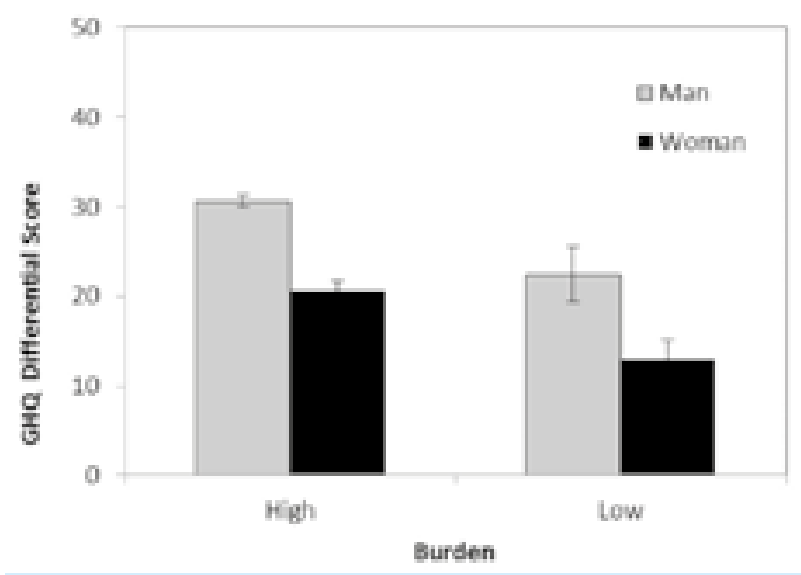

Figure-6. Representing significant interaction between gender and burden:

Standard Errors are represented in the figure by the error bars attached to each column.

explanation of it is that women were emotional and exhibiting high expressed emotions more frequently as compared to men. Thus, it is expected to the men to be focused on the reality and preferred to be rational rather than being emotional. Moreover women are traditionally considered to be responsible of caregiving and involved in household activities while at the same time men are considered to be bread winners and supporter of family. 


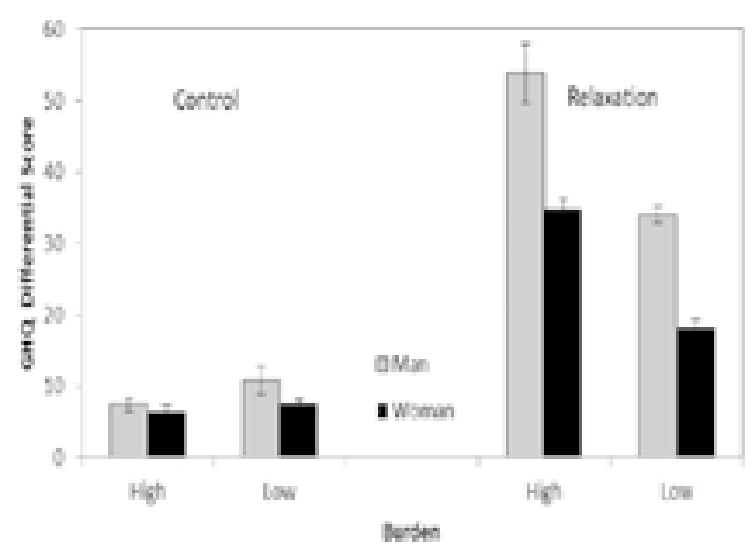

Figure-7. Representing significant interaction among gender, burden and training:

Standard Errors are represented in the figure by the error bars attached to each column.

Studies have shown that hopelessness about the future of patients creates stress, mental, physical and emotional problems in the mother of children with autism and children with Down syndrome. ${ }^{31}$ Women are the home makers and generally more sensitive towards the relationships while men are usually the bread winners for the family and it is not their traditional role to care for sick family members. ${ }^{32,33,34}$

Findings are also supported the hypothesis which assumed that relaxation training would help to mange the burden level and improved the mental health condition. It also showed significant interaction between burden and training and gender and training. Which showed relaxation training is helpful in every condition and has highly significant main effect and interaction with other variables. ${ }^{35}$ Researchers ${ }^{36}$ worked on relaxation training for anxiety: A ten years systematic review with meta-analysis find out significant consistency and efficacy of relaxation training with burden management. Outcome of the results are supported the hypothesis that high burden effected the GHQ's differential scores. Mental health of caregivers remains on stake when they have high level of burden because high burden level deteriorated the mental health functioning. In the same way, research was conducted on caregivers' stress when living together or apart from patients with chronic schizophrenia. Results found that chronic mental illness generally effected the overall functioning of caregivers and brought specific severe consequences on mental health. ${ }^{37}$ Moreover, it concluded that American workers suffer a mental health problems rooted in burden related problems. ${ }^{38}$

Results also indicated significant interaction between gender and training, burden and training but no interaction between gender, burden and no overall interaction among gender, burden and training. Researchers ${ }^{39,40}$ found that the caregivers of patients having negative symptoms of schizophrenia were suffering from high burden while those of patients with positive symptoms from low objective burden. Moreover physical, emotional, psychological, social problems, quality of life and financial pressures were the significant predictors of objective burden in the caregivers of dementia, epilepsy and schizophrenia. Similarly ${ }^{41}$ it was concludes that objective and subjective burden in the caregivers were highly associating with the severity of schizophrenic patients. One possible explanation of it is that caregivers experienced negative emotions like fatigue, barrenness, boredom, stress, frustration and in extreme cases they showed hostile attitude towards the patients. These symptoms occur when the caregivers having no understanding about the nature of the disease. They do not accept their role but get over enthusiastic although in the case of chronic illness like schizophrenia and epilepsy they become emotionally fatigued and usually express negative emotions. ${ }^{42}$

\section{Limitations and suggestions}

1. Diagnoses of the patients were not reconfirmed.

2. Age ranges of the caregivers were very broad.

3. Sub categories of the problems were ignored.

4. Other demographic variables such as education, time spent with the patients and numbers of supporters were not including in the major analysis.

5. Caregivers can be taken from the private health sectors for the sake of comparison between public and private health sectors.

6. Caregivers who belong to upper class and 
have enough resources for their patients can be included in the study.

7. In door patients can be included in the study for the comparison with outdoor patients.

8. Qualitative analysis is strongly recommended.

9. Equal numbers of caregivers of schizophrenia and epilepsy should have been included.

10. A comparison can be invited between chronic and acute problem.

\section{Implications}

This study will be helpful for the mantel health professionals and will facilitate the policy makers to include the caregivers in the plan while making strategies for the patients. This research can be supportive in the training of the caregivers to tackle the chronic illness like schizophrenia and epilepsy and can catch the attention of the researchers to explore the different dimensions of the caregiver's problems.

\section{CONCLUSION}

The caregivers are inevitable in chronic illness like schizophrenia and epilepsy. Caregiving is moral, social and religious obligation not to be ignored but this time consuming, hectic and exhausted way of living with patients of schizophrenia and epilepsy may lead to a mixture of psychological, physiological, emotional, and social problems. Relaxations training significantly reduce the burden and improve the mental health problems. Copyright(C) 15 Mar, 2017.

\section{REFERENCES}

1. Baiyewu O, Smith-Gamble V, Akinbiyi A, Lane KA, Hall KS, Ogunniyi A, Gureje O, Hendrie HC. Behavioral and caregiver reaction of dementia as measured by the neuropsychiatric inventory in Nigerian community residents. International Psychogeriatrics. 2003 Dec 1; 15(04):399-409.

2. Blieszner R, Alley JM. Family caregiving for the elderly: An overview of resources. Family Relations. 1990 Jan 1:97-102.

3. Schulz R, Martire LM. Family caregiving of persons with dementia: prevalence, health effects, and support strategies. The American journal of geriatric psychiatry. 2004 Jun 30; 12(3):240-9.

4. Haley WE, Levine EG, Brown SL, Berry JW, Hughes GH. Psychological, social, and health consequences of caring for a relative with senile dementia. Journal of the American Geriatrics Society. 1987 May 1; 35(5):40511.

5. Brody TA, Flores J, French JB, Mello PA, Pandey A, Wong SS. Random-matrix physics: spectrum and strength fluctuations. Reviews of Modern Physics. 1981 Jul 1; 53(3):385.

6. Nijboer C, Tempelaar R, Sanderman R, Triemstra M, Spruijt RJ, Van Den Bos GA. Cancer and caregiving: the impact on the caregiver's health. Psycho oncology. 1998 Jan 1; 7(1):3-13.

7. Budd RJ, Oles G, Hughes IC. The relationship between coping style and burden in the carers of relatives with schizophrenia. Acta Psychiatrica Scandinavica. 1998 Oct $1 ; 98(4): 304-9$.

8. Osman CB, Alipah B, Tutiiryani MD, Ainsah O. Depressive disorders and family functioning among the caregivers of patients with schizophrenia. East Asian Archives of Psychiatry. 2010 Sep 1; 20(3):101.

9. Montgomery RJ, Gonyea JG, Hooyman NR. Caregiving and the experience of subjective and objective burden. Family relations. 1985 Jan 1:19-26.

10. Pilisuk M, Parks SH. Caregiving: Where families need help. Social Work. 1988 Sep 1; 33(5):436-40.

11. Zarit $\mathrm{SH}$, Edwards $\mathrm{AB}$. Family caregiving: research. Handbook of the clinical psychology of ageing. 2008 Apr 15:255.

12. Pickard AS, Lin HW, Knight SJ, Sharifi R, Wu Z, Hung SY, Witt WP, Chang $\mathrm{CH}$, Bennett $\mathrm{CL}$. Proxy assessment of health-related quality of life in African American and white respondents with prostate cancer: perspective matters. Medical care. 2009 Feb; 47(2):176.

13. Sethi S, Bhargava SC, Dhiman V. Study of level of stress and burden in the caregivers of children with mental retardation. Eastern Journal of Medicine. 2007 Jan $1 ; 12(1 / 2): 21$.

14. Bowlin SJ, Medalie JH, Flocke SA, Zyzanski SJ, Goldbourt U. Epidemiology of intermittent claudication in middle-aged men. American journal of epidemiology. 1994 Sep 1; 140(5):418-30.

15. MacNeil G, Kosberg JI, Durkin DW, Dooley WK, DeCoster J, Williamson GM. Caregiver mental health and potentially harmful caregiving behavior: The central role of caregiver anger. The Gerontologist. 2010 Feb 1; 50(1):76-86.

16. Black DS, Cole SW, Irwin MR, Breen E, Cyr NM, Nazarian N, Khalsa DS, Lavretsky $H$. Yogic meditation 
reverses NF-KB and IRF-related transcriptome dynamics in leukocytes of family dementia caregivers in a randomized controlled trial. Psychoneuroendocrinology. 2013 Mar 31; 38(3):348-55.

17. Oberst MT, Thomas SE, Gass KA, Ward SE. Caregiving demands and appraisal of stress among family caregivers. Cancer nursing. 1989 Aug 1; 12(4):209-15.

18. Boerner K, Schulz R, Horowitz A. Positive aspects of caregiving and adaptation to bereavement. Psychology and aging. 2004 Dec; 19(4):668.

19. Kausar R, Powell GE. Coping and psychological distress in carers of patients with neurological disorders. Asia Pacific Disability Rehabilitation Journal (India). 1999; 10(2):64-8.

20. Mahmood A, Niaz S, Rashid U, Chaudhry HR. Expressed emotions and schizophrenia in Pakistan. Pakistan Journal of Medical Sciences. 2006; 22(4):424.

21. Aziz H, Ali SM, Frances P, Khan MI, Hasan KZ. Epilepsy in Pakistan: A population $\square$ based epidemiologic study. Epilepsia. 1994 Sep 1; 35(5):950-8.

22. McDonald WM, Richard IH, DeLong MR. Prevalence, etiology, and treatment of depression in Parkinson's disease. Biological psychiatry. 2003 Aug 1; 54(3):36375 .

23. Fann JR, Thomas-Rich AM, Katon WJ, Cowley D, Pepping M, McGregor BA, Gralow J. Major depression after breast cancer: a review of epidemiology and treatment. General hospital psychiatry. 2008 Apr 30; 30(2):112-26.

24. Reinhard SC, Gubman GD, Horwitz AV, Minsky S. Burden assessment scale for families of the seriously mentally ill. Evaluation and program planning. $1994 \mathrm{Jul}$ $1 ; 17(3): 261-9$.

25. Ilyas, R., \& Malik, F. (2009). Expresses emotion and burden of care among relatives of patients with schizophrenia. Thesis, GCU, Lahore. Session 2007-09.

26. Platt $S$. Measuring the burden of psychiatric illness on the family: an evaluation of some rating scales. Psychological medicine. 1985 May 1; 15(02):383-93.

27. Goldberg D, Williams P, Williams P. A user's guide to the General Health Questionnaire. NferNelson; 1988.

28. Meltzer H, Ford T, Goodman R, Vostanis P. The burden of caring for children with emotional or conduct disorders. International journal of family medicine. 2011 May 31; 2011.

29. Barbosa A, Figueiredo D, Sousa L, Demain S. Coping with the caregiving role: Differences between primary and secondary caregivers of dependent elderly people. Aging \& Mental Health. 2011 May 1; 15(4):490-9.

30. Kohn-Wood LP, Wilson MN. The context of caretaking in rural areas: family factors influencing the level of functioning of seriously mentally ill patients living at home. American Journal of Community Psychology. 2005 Sep 1; 36(1-2):1-3.

31. McKendrick N. Home demand and economic growth: a new view of the role of women and children in the industrial revolution. Historical perspectives: Studies in English thought and society in honour of JH Plumb. 1974:152-210.

32. Miller B, Cafasso L. Gender differences in caregiving: fact or artifact?. The Gerontologist. 1992 Aug 1; 32(4):498-507.

33. Barusch AS, Spaid WM. Gender differences in caregiving: why do wives report greater burden?. The Gerontologist. 1989 Oct 1; 29(5):667-76.

34. Yee JL, Schulz R. Gender differences in psychiatric morbidity among family caregivers a review and analysis. The Gerontologist. 2000 Apr 1; 40(2):147-64.

35. Fisher PA, Laschinger HS. A Relaxation Training Program to Increase Self $\square$ Efficacy for Anxiety Control in Alzheimer Family Caregivers. Holistic Nursing Practice. 2001 Jan 1; 15(2):47-58.

36. Manzoni GM, Pagnini F, Castelnuovo G, Molinari E. Relaxation training for anxiety: a ten-years systematic review with meta-analysis. BMC psychiatry. 2008 Jun 2; 8(1):1.

37. Laidlaw TM, Coverdale JH, Falloon IR, Kydd RR. Caregivers' stresses when living together or apart from patients with chronic schizophrenia. Community Mental Health Journal. 2002 Aug 1; 38(4):303-10.

38. Afolayan JA, Dairo BA. Stress in the workplace of nurses and midwives in Nigeria. Journal of Behavioural Sciences. 2009 Jan 1; 19(1/2):1.

39. Provencher HL, Mueser KT. Positive and negative symptom behaviors and caregiver burden in the relatives of persons with schizophrenia. Schizophrenia Research. 1997 Jul 25; 26(1):71-80.

40. Brouwer WB, Van Exel N, Van De Berg B, Dinant HJ, Koopmanschap MA, Van Den Bos GA. Burden of caregiving: evidence of objective burden, subjective burden, and quality of life impacts on informal caregivers of patients with rheumatoid arthritis. Arthritis Care \& Research. 2004 Aug 15; 51(4):570-7. 
41. Schene AH. Objective and subjective dimensions of family burden. Social Psychiatry and Psychiatric Epidemiology. 1990 Nov 1; 25(6):289-97.

42. Marks R, Allegrante JP. A review and synthesis of research evidence for self-efficacy-enhancing interventions for reducing chronic disability: implications for health education practice (part II). Health promotion practice. 2005 Apr; 6(2):148-56.

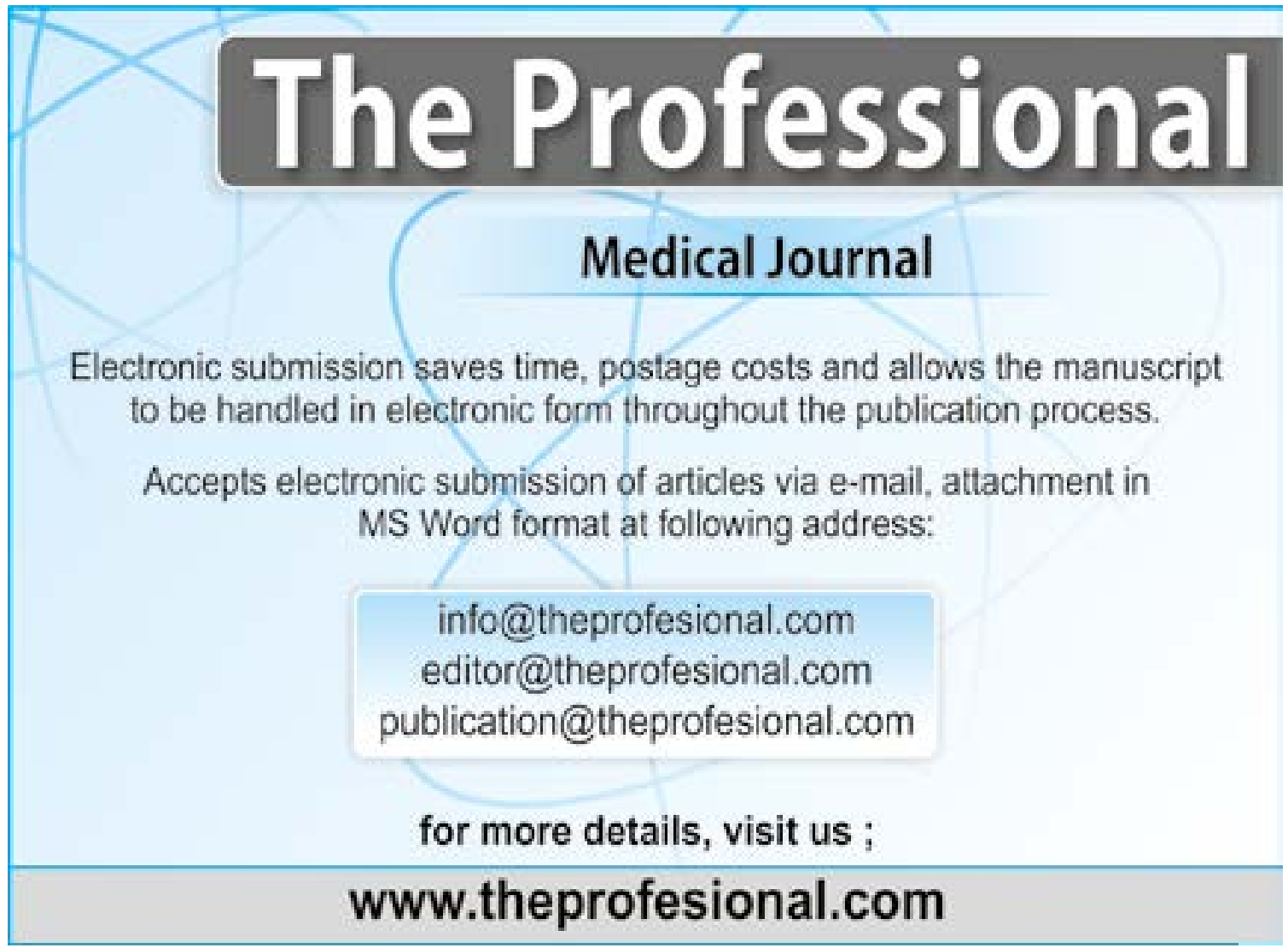

AUTHORSHIP AND CONTRIBUTION DECLARATION

\begin{tabular}{c|l|l|l|}
\hline Sr. \# & \multicolumn{1}{|c|}{ Author-s Full Name } & Contribution to the paper & Author=s Signature \\
\hline 1 & Wahida Anjum & Main Author & \\
\hline
\end{tabular}

